Other groups have reported similar results with primary medical treatment and radiotherapy (I E Smith et al and C Jacquillat et al, Joint National Cancer Institute and Italian Society for Research into Tumours Symposium: Biology and therapy of breast cancer, Genoa, 1989.) Not all groups reported how many patients subsequently required mastectomy, however, but Smith et al from the Royal Marsden Hospital reported that $18 \%$ of 57 patients required mastectomy after a median follow up of 19 months (I E Smith et al, 1989). Only 15 of these patients received chemotherapy, the remainder being treated by endocrine therapy. Should these results be confirmed the next step will be to treat tumours of less than $3 \mathrm{~cm}$, thus challenging the role of surgery in the management of breast cancer.

The advantages of primary medical treatment include in vivo monitoring of drug response, a decrease in tumour size before surgery, and, when combined with radiotherapy, the possibility of avoiding surgery altogether. This form of treatment also offers the potential for studying biological changes associated with drug response and disease progression, including the phenomenon of multiple drug resistance associated with expression of $\mathrm{P}$ glycoprotein. ${ }^{14}$

There are no published data on the quality of life of patients given primary medical treatment for operable breast cancer, but we find that most patients tolerate it well and their quality of life is no worse than that of patients receiving adjuvant chemotherapy after surgery. Women are often surprisingly willing to have primary medical treatment, especially if it replaces surgery.

Nevertheless, several problems do exist. Firstly, if primary medical treatment is used for tumours of less than $2 \mathrm{~cm}$ a substantial proportion of patients with node negative disease will receive chemotherapy who do not need it, as $70 \%$ of these women are alive and well 10 years after conventional treatment with no adjuvant chemotherapy. Another problem is residual tumour, which in one study was present in $96 \%$ of patients after treatment. ${ }^{1}$ In another study $74 \%$ of patients undergoing mastectomy after chemotherapy had axillary node disease. ${ }^{15}$ Radiotherapy may remove residual tumour, but uncertainty may exist even after biopsy owing to sampling error. This problem would be particularly important in young women, who would be prime candidates for this form of treatment.

Biological markers of response to chemotherapy would be helpful in selecting patients for primary medical treatment. The only biological feature predictive of tumour response is a high $S$ phase fraction, which indicates a high proliferative tumour rate. ${ }^{16}$ Other characteristics of the tumour, such as histological grade, expression of oestrogen receptor, or measures of growth kinetics, seem to be unhelpful.' Almost a third of patients with node negative disease die of their disease ${ }^{17}$; if they could be reliably identified chemotherapy for them would be justified.

Other studies to identify subgroups with a poor prognosis have found that the proto-oncogene c-erb B2 is expressed in up to two fifths of breast cancers ${ }^{18}{ }^{19}$ and is associated with early relapse and poor survival, ${ }^{18} 20$ although not all authors have confirmed these findings. ${ }^{21}$ Expression of epidermal growth factor receptor has also been associated with poor survival, ${ }^{22}$ as has cathepsin $\mathrm{D}$, an oestrogen stimulated lysosomal enzyme that seems to be especially useful in identifying patients with node negative disease who are at high risk of relapse. ${ }^{23}$

Primary medical treatment is accepted for locally advanced breast cancer and now seems to have a further role in downstaging operable breast cancer, though this approach is still to be evaluated. Whether it can replace surgery completely remains uncertain, especially as it is likely to be offered to younger patients. The future may lie instead in identifying subgroups of patients at high risk and whose tumours express epidermal growth factor receptor, c-erb B2 oncogene, and cathepsin $\mathrm{D}$, to see whether primary medical treatment can improve their survival. The results of controlled trials are eagerly awaited.

Z RAYTER

R F PHIPPS

Senior Surgical Registrars,

Royal Marsden Hospital,

London SW3 6JJ

(Correspondence to Mr Rayter)

1 Bonnadonna G. Conceptual and practical advances in the management of breast cancer. $\mathcal{F}$ Clin Oncol 1989;7:138-97

2 Veronesi U, Caccozzi R, Del Vechio M. Comparing radical mastectomy with quadrantectomy, axillary dissection and radiotherapy in patients with small cancers of the breast. $N$ Engl $\mathcal{J}$ Med 1981;305:6-11.

3 Sarrazin D, Le M, Rouesse J, et al. Conservative treatment versus mastectomy in breast cancer tumours with microscopic diameter of $20 \mathrm{~mm}$ or less. Cancer 1984;53:1209-13.

4 Atkins $\mathrm{H}$, Hayward JL, Klugman DJ, Wayte AB. Treatment of early breast cancer: a report after ten years of a clinical trial. Br Med f 1972; ii:423-9.

5 Rayter Z, Gazet J-C, Ford HT, Easton DF, Coombes RC. Comparison of conservative surgery and radiotherapy with mastectomy in the treatment of early breast cancer. Eur $\mathcal{F}$ Surg Oncol 1990 (in

6 Veronesi U, Saccozzi R, Del Vecchio $M$, et al. Comparing radical mastectomy with quadrantectomy, axillary dissection and radiotherapy in patients with small cancers of the breast. $N$ Engl $\mathcal{F}$ Med 1981;305:6-11.

7 Henderson IC. The treatment of advanced breast cancer. In: Williams CJ, Whitehouse JMA, eds. Recent advances in clinical oncology. 2. Edinburgh: Churchill Livingstone, 1986:135-56.

8 Harris AL, Countwell BM, Carmichael J, et al. Comparison of short-term and continuous chemotherapy (Mitozantrone) for advanced breast cancer. Lancet 1990;335:186-90.

9 Powles TJ, Smith IE, Ford HT, Coombes RC, Jones JM, Gazet J-C. Failure of chemotherapy to prolong survival in a group of patients with metastatic breast cancer. Lancet 1980;i:580-4.

10 Paterson AHG, Szaford O, Cornish F, Lees AW, Hanson J. Effect of chemotherapy on survival in metastatic breast cancer. Breast Cancer Res Treat 1982;1:357-60.

11 A'Hern RP. Ebbs SR, Baum MB. Does chemotherapy improve survival in advanced breast cancer? A statistical overview. Br $\mathcal{F}$ Cancer 1988;57:615-8.

12 Bonnadonna G, De Lena M, Brombilla C, et al. Combination chemotherapy and combined modality in disseminated and locally advanced breast cancer. In: Montague ACV, Stonesifer GL, Lewison EF, eds. Breast cancer, progress in clinical and biological research. New York: Alan Liss, 1977:437-58.

13 De Lena $M$, Zucali R, Vigantotti G, et al. Combined chemotherapy-radiotherapy approach in locally advanced (T3b-T4 breast cancer. Cancer Chemother Pharmacol 1978;1:53-9.

Schneider J, Bak M, Efferth TH, Kaufmann M, Mattern J, Volm M. P-Glycoprotein expression in treated and untreated human breast cancer. Brf Cancer 1989;60:815-8.

5 Swain SM, Sarace RA, Bagley CS, et al. Neoadjuvant chemotherapy in combined modality approach of locally advanced non-metastatic breast cancer. Cancer Res 1987;47:3889-94.

16 Remvikos Y, Beuzeboc P, Zajdelan A, Voillemot H, Magdele\# acrat H, Pouillart P. Correlation of pre-treatment proliferative activity of breast cancer with the response to cytotoxic chemotherapy. $7 N C I$ 1989;81:1383-7.

17 Fisher B, Baner M, Wickerham L, Redmond C, Fisher ER. Relationship of the numbers of positive axillary nodes to thet prognosis of patients with primary breast cancer. Cancer 1983;52:1551-7.

18 Slamon DJ, Clark GM, Wong SG, Levin WJ, Ullrich A, McGuire WL. Human breast cancer correlation of relapse and survival with amplification of the HER-2/neu oncogene. Science 1987;235:177-82.

19 Berger MS, Locher GW, Saurer S, et al. Correlation of c-erb B2 gene amplification and protein expression in human breast carcinoma with nodal status and nuclear grading. Cancer Res 1988;48:1238-43.

20 Wright $\mathrm{C}$, Angus B, Nicholson $\mathrm{S}$, et al. Expression of $\mathrm{c}$-erb B2 oncoprotein: a prognostic indicator in human breast cancer. Cancer Res 1989;49:2087-90.

21 Ali IU, Campbell G, Lideream R, Callahan R. Lack of evidence for the prognostic significance of $c$ erb B2 amplication in human breast cancer. Oncogene Res 1988;3:139-46.

22 Sainsbury JRC, Needham GK, Malcolm A, Farndon JR, Harris AL. Epidermal growth factor as a predictor of early recurrence and death from breast cancer. Lancet 1987;i:1398-402.

23 Spyratos F, Maudelonde T, Brouillet JP, et al. Cathepsin D: an independent prognostic factor for metastasis in breast cancer. Lancet 1989;ii:1115-8.

\section{Hypothermia: dead or alive?}

\section{Some patients deserve heroic measures}

At this time of year exposure on the hills, cold immersion, or collapse induced by alcohol may all cause hypothermia in healthy people. Whether they do so depends greatly on the individual's internal insulation from subcutaneous fat and on recent carbohydrate intake. Such intake is particularly important in preventing alcohol induced hypothermia, caused by thermoregulatory failure due to hypoglycaemia. ${ }^{1-3}$

The principles of treating simple hypothermia remain straightforward and generally uncontroversial for victims who still have a carotid pulse and respiration, however slow and difficult these may be to detect. External rewarming in the horizontal position by warm air, or by a warm bath not hot enough to be painful to the rescuer's elbow, is usually effective. A drink containing sugar or, rarely, intravenous 
glucose or saline may be given as rewarming proceeds. Otherwise there should be minimal interference with the patient. In particular measures that may precipitate ventricular fibrillation should be avoided, such as unnecessary cardiac massage or laryngeal intubation, or, worst of all, intravenous injection of adrenalin.

More active treatment has long been known to produce recovery after hypothermia has caused ventricular fibrillation or arrest, but it is often forgotten that it can do so after arrest lasting an hour and sometimes considerably longer. ${ }^{+}$In Sweden anyone found apparently dead in cold air or water is routinely regarded as a candidate for emergency treatment rather than a casualty for the mortuary. This is particularly necessary as complicating factors such as "paradoxical undressing" by victims as hypothermia develops 5 may mislead a rescuer into thinking that they were victims of assault and injury rather than simple hypothermia. The problem is less common in countries with less cold winters, but the same principles should clearly be adopted in cold weather anywhere.

Simple external warming, with or without external cardiac massage and artificial ventilation, has seldom revived adults from -hypothermic cardiac arrest or ventricular fibrillation. This is probably because rewarming is so slow that many hours may elapse before cardiac temperature rises to the point at which spontaneous cardiac rhythm restarts or defibrillation can succeed. Extracorporeal circulation - to provide vascular rewarming as well as maintenance of circulation - is therefore the treatment of choice in hypothermic arrest. It may be achieved by femoral or cardiopulmonary bypass and succeeds in a high proportion of suitable cases. ${ }^{46}$

The effort and resources needed for such invasive treatment have prompted a search for means of identifying victims capable of being revived. A recent paper suggests that hyperkalaemia may be a marker for non-recoverable hypothermia as hypothermic victims of avalanches had very high plasma potassium concentrations (mean $14.5 \mathrm{mmol} / \mathrm{l}$ ) and could not be revived. ${ }^{7}$ Patients with similar core temperatures after drug intoxication or simple exposure to cold had lower plasma potassium concentrations (mean $3.5 \mathrm{mmol} / \mathrm{l}$ ) and could be revived, though some died later from other conditions. The high plasma potassium concentration probably reflected asphyxia as well as cardiopulmonary arrest in the avalanche group, all of whom were clinically dead. All of the 15 patients in the second group seem to have had a heart beat and respiration when found, although two had a brief arrest at some stage. The value of a very high serum potassium concentration as a prognostic indicator in uncomplicated hypothermia is therefore uncertain, but it may provide a guide to cases in which resuscitation cannot succeed for other reasons. Early measurements of plasma potassium concentrations might help in focusing attention on those victims who could be revived by the heroic measures needed in hypothermic cardiopulmonary arrest.

Most cases of urban hypothermia in Britain are not due to simple exposure and need different management. ${ }^{8}$ Most of these people have collapsed as a result of serious disease and have cooled as a result of the illness and immobility, often in heated rooms. ${ }^{9}$ Blankets and warm air inhalation can be used to prevent further cooling in any hypothermic person. ${ }^{10}$ More active rewarming of people who have collapsed in their homes, however, is usually best delayed until admission to hospital, where the underlying disease, which is often masked by hypothermia, can be diagnosed and treated effectively.

W R KEATINGE

Professor of Physiology,

Basic Medical Sciences,

Queen Mary and Westfield College,

London E1 4NS
1 Madison LL. Ethanol-induced hypoglycaemia. Advances in Metabolic Disorders 1968;3:85-109. 2 Haight JSJ, Keatinge WR. Failure of thermoregulation in the cold during hypoglycaemia induced by exercise and ethanol. $\mathcal{F}$ Physiol (Lond) 1973;229:87-97

3 Gale EAM, Bennett T, Green JH, MacDonald IA. Hypoglycaemia, hypothermia and shivering in man. Clin Sci 1981;61:463-9.

4 Althaus U, Aeberhard P, Schupbach P, et al. Management of profound accidental hypothermia with cardiorespiratory arrest. Ann Surg 1982;195:492-5.

Wedin B, Vanggaard L, Hirvonen J. "Paradoxical undressing" in fatal hypothermia. 7 Forensic Sci 1979;24:543-53.

Splittgerber FH, Talbert JG, Sweezer WP, et al. Partial cardiopulmonary bypass for core rewarming in profound accidental hypothermia. Am $\mathcal{F}$ Surg 1986;52:407-12.

Schaller M-D, Fischer AP, Perret CH. Hyperkalemia. A prognostic factor during acute severe hypothermia. FAMA 1990;264:1842-5.

Slater DN. Death from hypothermia: are current views on causative factors well founded? $B M 7$ 1988;296:1643-4.

Woodhouse P, Keatinge WR, Coleshaw SRK. Factors associated with hypothermia in patients admitted to a group of inner city hospitals. Lancet 1989;ii:1201-5.

10 Lloyd EL, Croxton D. Equipment for the provision of airway warming (insulation) in the treatment of accidental hypothermia in patients. Resuscitation 1981;9:61-5.

\section{Cyclosporin: use outside transplantation}

\section{Promising, but long term follow up is essential}

The success of cyclosporin $\mathrm{A}$ in allograft transplantation stems from its selective immunological action on $\mathrm{T}$ lymphocytes and its much lower ratio of risk to benefit than cytotoxic drugs. Enthusiasm for the drug is tempered by its potential toxicity, particularly nephrotoxicity, ${ }^{1}$ and by the risks associated with chronic immunosuppression. Nevertheless, cyclosporin's potential is being investigated in a wide variety of autoimmune diseases..$^{23} \mathrm{~A}$ recent symposium organised by the Royal Society of Medicine reached some consensus on the use of cyclosporin outside transplantation and on its relative efficacy and potential.

Cyclosporin inhibits $\mathrm{T}$ lymphocyte activation and proliferation but is not cytotoxic. Unlike corticosteroids, azathioprine, and other cytotoxic drugs, it inhibits selectively both antigen induced activation of $\mathrm{CD} 4+$ ( $\mathrm{T}$ helper) lymphocytes and the production by these cells of interleukin 2 and other cytokines. ${ }^{45}$ Cyclosporin can also interrupt active immune responses, as shown by its efficacy in treating autoimmune diseases - presumably by blocking the secretion of cytokines by lymphocytes. The drug inhibits the in vivo transcription of genes encoding interleukin 2 and interferon $\gamma^{6}$ and blocks the expression of interleukin 2 receptors, whose induction is essential to $T$ cell proliferation.

It is now clear that cyclosporin reversibly inhibits early, calcium dependent events in $\mathrm{T}$ lymphocyte activation and that there are probably several molecular targets within the cell membrane, cytosol, and nucleus. ${ }^{4}$ The most exciting new developments concern the uptake and concentration of cyclosporin in cystolic and nuclear target sites mediated by cyclophilin, a recently discovered enzyme (peptidylprolyl isomerase). The relation between $T$ cell activation and the function of this enzyme is unknown, but, by interfering with cyclophilin's role in the folding of regulatory peptides, the drug may prevent the formation or function of nuclear factors that regulate the expression of cytokine genes. ${ }^{7}$ Recent evidence suggests that cyclosporin blocks the function of a gene termed NF-AT (nuclear factor of activated T cells), which may be the immediate or early regulator of $\mathrm{T}$ cell activation. ${ }^{8}$ These properties of cyclosporin are shared by the novel anti-T cell agent FK-506, which may also have important clinical potential..$^{10}$

In view of its molecular action not surprisingly cyclosporin will induce and maintain remission in many autoimmune disorders, particularly those with mechanisms mediated by $\mathrm{T}$ cells. Cyclosporin's effectiveness has been established in 